\title{
A práxis-crítica na tradição do pensamento social brasileiro
}

\section{Critical praxis in the tradition of the Brazilian social though}

\author{
Maria Ceci Misoczky \\ Rafael Kruter Flores*
}

A proposta dos editores foi de uma reflexão sobre o estado da arte da perspectiva crítica no Brasil. Consideramos que é muito importante explorar a riquíssima tradição crítica no pensamento social brasileiro, ${ }^{1}$ bem como as possíveis aprendizagens e inspirações que nele podemos encontrar para potencializar a prática da crítica em nosso espaço disciplinar. Após uma retomada do que entendemos por práxis crítica, trazemos para o diálogo, com a brevidade que o espaço exige, alguns cidadãos brasileiros, críticos, ativistas e, portanto, intelectuais: Caio Prado Júnior, Ruy Mauro Marini e Darcy Ribeiro. ${ }^{2}$ O que os une, apesar de tantas diferenças, é uma capacidade enorme de se comprometer com os problemas e as lutas de seu tempo, de teorizar para a ação e, também, de agir.

Eis porque, em oposição ao materialismo, o aspecto ativo foi desenvolvido de maneira abstrata no idealismo, que, naturalmente, desconhece a atividade real, sensível, como tal. Feuerbach quer objetos sensíveis - realmente distintos dos objetos do pensamento: mas não apreende a própria atividade humana como atividade objetiva. Por isso, em A Essência do Cristianismo, considera apenas o comportamento teórico como o autenticamente humano, enquanto a práxis só é apreciada e fixada em sua forma fenomênica judaica e suja. Eis porque não compreende a importância da atividade "revolucionária”, "práxis-crítica”.

KARL MARX

Para esclarecer o entendimento de práxis que adotamos, é preciso distingui-la de atividade. Atividade (ou ação) se refere ao ato ou conjunto de atos através do qual um sujeito ativo modifica uma matéria prima dada. Essa é uma qualificação por demais inespecífica, o ponto de abarcar atividades instintivas ou biológicas e, mesmo, atos que não sejam especificamente humanos. Para Vásquez (2007, p.219), "a atividade propriamente humana apenas se verifica quando os atos dirigidos a um objeto para transformá-lo se iniciam com um resultado ideal, ou fim, e terminam com um resultado ou produto efetivo, real." Há, portanto, a interferência da consciência; ou seja, o real almejado existe anteriormente como produto ideal da consciência, como antecipação do desejado. Mais que isso: como no processo de realização o ideal antecipado na consciência sofre modificações, para falar de atividade humana "é preciso que se formule nela um resultado ideal, um fim a cumprir, como ponto de partida, e uma intenção de adequação, independentemente de como se plasme, definitivamente, o modelo ideal originário" (VÁSQUEZ, 2007, p.221).

•Doutora em Administração pela Universidade Federal do Rio Grande do Sul. Docente da Escola de Administração da Universidade Federal do Rio Grande do Sul PPGA/UFRGS. Coordenadora do Grupo de Pesquisa Organização e Práxis Libertadora. Endereço: Escola de Administração/UFRGS - Av. Washington Luis 855 Porto alegre/Rio Grande do Sul - Brasil - CEP: 90010-460 - E-mail: mcamisoczky@ea.ufrgs.br

- Mestre em Administração/Organizações. Doutorando no Programa de Pós-Graduação em Administração- Universidade Federal do Rio Grande do Sul - UfRGS. Pesquisador do Grupo de Pesquisa Organização e Práxis Libertadora. Endereço: Fernandes Vieira, 533/203 - Bom Fim - - Porto Alegre/Rio Grande do Sul - Brasil - CEP: 90035091. Email: rkflores@ea.ufrgs.br

${ }^{1}$ Este texto é dedicado a Paulo Emílio Matos Martins, incansável estudioso e disseminador do pensamento social brasileiro.

${ }^{2}$ Paulo Freire certamente tem um lugar de honra neste grupo. No entanto, como é abordado no artigo "Bloch, Gramsci e Paulo Freire: referências fundamentais para os atos da denúncia e do anúncio", nesta edição, apenas reiteramos aqui sua ênfase em um componente estratégico fundamental da práxis libertadora, a educação como prática de liberdade. Em Paulo há uma enorme clareza no entendimento de que o ser humano não pode ser compreendido fora de suas relações com o mundo, que ele é um ser da práxis, da ação e da reflexão; que nas suas relações com o mundo e através de sua ação sobre ele, os seres humanos atuando transformam, transformando criam uma realidade (FREIRE, 1979). 
Há aqui uma distinção entre atividade teórica e práxis. Ainda que a prática teórica modifique percepções, representações ou conceitos, seu fim imediato é elaborar ou transformar idealmente para obter, como produtos, teorias que expliquem a realidade ou que prefigurem uma realidade futura. A atividade teórica proporciona um conhecimento indispensável para transformar a realidade, traça fins que antecipam o sentido dessa transformação, embora ainda sejam transformações no âmbito das ideias sobre o mundo, e não do próprio mundo (MARX, 1999; VÁSQUEZ, 2007).

Como indica Marx (1999), trata-se não só de interpretar o mundo, mas de transformá-lo. É, portanto, quando a atividade teórica se vincula conscientemente à prática, quando se propõe a ser instrumento para a transformação da realidade e é concebida em função da ação revolucionária, que podemos falar de uma práxis teórica.

Entre a teoria e a atividade prática transformadora se insere um trabalho de educação das consciências, de organização dos meios materiais e planos concretos de ação; tudo isso como passo indispensável para desenvolver ações reais efetivas. Nesse sentido, uma teoria é prática quando materializa, por uma série de mediações, o que antes só existia idealmente, como conhecimento da realidade ou antecipação ideal de transformação. (VÁSQUEZ, 2007, p.235-236)

Na mesma direção, Gramsci (2006, p.114) indica que a atividade teórica que se quer uma concepção crítica coerente, "responde a determinados problemas colocados pela realidade e, também, precisa ser socializada para se tornar base de ações vitais".

Para Löwy (2000, p.59), o conceito de filosofia da práxis formulado por Gramsci destaca a descontinuidade do pensamento marxista em relação aos discursos filosóficos dominantes:

rejeitando tanto o velho materialismo da filosofia das luzes - mudar as circunstâncias para libertar o homem (com seu corolário político lógico: o apelo ao déspota esclarecido ou a uma elite virtuosa) quanto o idealismo neo-hegeliano (liberar a consciência humana para mudar a sociedade).

Em vez disso, afirma o núcleo central do pensamento político marxista:

a revolução, como práxis autolibertadora, é simultaneamente a mudança radical das estruturas econômicas, sociais e políticas, e a tomada de consciência, pelas vítimas do sistema, de seus verdadeiros interesses, a descoberta das ideias, aspirações e valores novos, radicais e libertários. (LÖWY, 2000, p.60)

As relações entre teoria e prática são, portanto, de dependência mútua: a prática é o fundamento da teoria; a prática coloca exigências e funciona como critério de validade da teoria; a prática é o que permite à teoria superar suas limitações anteriores; a teoria não se desenvolve em prol da própria teoria, mas em nome da práxis - interpretação e transformação da realidade.

O passado trás consigo um índice misterioso, que o impele à redenção. Pois não somos tocados por um sopro do ar que foi respirado antes? Não existem, nas vozes que escutamos, ecos das vozes que emudeceram? Não têm as mulheres que cortejamos irmãs que elas não chegaram a conhecer? Se assim é, existe um encontro secreto, marcado entre as gerações precedentes e a nossa. Alguém na terra está à nossa espera. Nesse caso, como a cada geração, foi-nos concedida uma frágil força messiânica para a qual o passado dirige um apelo. Esse apelo não pode ser rejeitado impunemente. O materialista histórico sabe disso.

WALTER BENJAMIN 


\section{Caio Prado Júnior}

Filho de família paulista tradicional, Caio Prado Júnior (1907-1990) foi comunista e historiador, geógrafo e filósofo, economista com formação em direito, deputado constituinte paulista e preso político. Secco (2008) situa o curto espaço de tempo durante o qual Caio Prado Júnior promoveu uma profunda mudança na concepção de Brasil vigente até então: na política nacional, o período entre o início do tenentismo (1922) e a instauração do Estado Novo (1937); na militância, com seu ingresso no Partido Comunista Brasileiro (PCB), em 1931, até sua eleição à Assembleia Constituinte Paulista em 1947; na elaboração intelectual, a gestação da inovação historiográfica que sua obra representou entre 1933 (Evolução política do Brasil) e 1942 (Formação do Brasil Contemporâneo).

Para desenvolver seu projeto, baseado na compreensão de que "nossos problemas eram os problemas da nossa sociedade e da nossa articulação com o mercado mundial" (KONDER, 1991, p.30), Caio não podia se apoiar nas orientações do PCB, onde a teorização marxista orgânica era quase nula. Foi capaz, então, "de combinar suas leituras de Marx com a vivência e a compreensão do Brasil” (SECCO, 2008, p.37).

O historiador materialista comprometido com um projeto revolucionário precisa reconstituir o quadro, compreender os problemas postos pela vida, avaliar as condições materiais para poder entender criticamente as iniciativas, as propostas, os anseios, o ânimo com que os homens se movem na arena de luta na qual se veem colocados. Caio Prado Júnior assimilou essa dimensão do pensamento de Marx e por isso foi capaz de aplicar pioneiramente entre nós a concepção da história elaborada pelo autor d'O Capital. (KONDER, 1991, p.32)

Nas palavras de Pinheiro (1982): "o marxismo de Caio Prado Júnior não é o recitativo de fórmulas ou citações, mas uma via de interpretação de um viajante infatigável e implacável pela realidade de seu próprio país e de seu tempo".

Caio, o ativista, editou jornais; aplicou dinheiro em uma gráfica clandestina; conheceu a vida dos trabalhadores e durante toda sua vida desejou ouvi-los; publicou cartas nos jornais em defesa do comunismo; participou de muitas organizações, como o Socorro Vermelho e a Cooperativa Internacional dos Trabalhadores, além de células de base do Partido, onde fazia de tarefas manuais a discursos e palestras; foi fundador do Clube de Artistas Modernos; dirigiu A Plateia e nela escreveu vários artigos sobre o programa anti-imperialista da Aliança Nacional Libertadora (ANL); divergiu do PCB em seu apoio ao Estado Novo, o que redundou em sua expulsão oficial, mas não em seu desligamento prático; foi o principal criador da Frente Popular por Pão, Terra e Liberdade; foi preso (1935), por dois anos, após o movimento conhecido como Intentona Comunista; partiu para o exílio na França, onde ficou outros dois anos e se ligou ao Partido Comunista Francês; fundou a Editora Brasiliense (1943); pelo PCB, candidatou-se sem sucesso a deputado federal, elegeu-se deputado na Assembleia Constituinte Paulista em 1947, foi cassado e preso por três meses. Caio se candidatou duas vezes a professor da USP: na primeira (1954) foi aprovado, mas não nomeado; na segunda, (1968) o concurso foi cancelado. Em 1970, foi preso novamente sob a acusação de incitar a luta armada contra a ditadura (SECCO, 2008; WIDER, 2007).

Caio, o pensador do Brasil, revelou os elementos materiais que definiram sua a organização econômica a partir da colonização: o país foi estruturado para atender às necessidades externas, não para alimentar seu mercado interno; tomando assim a economia colonial como concreto empírico inserido na totalidade que é o capitalismo mundial. É dele a afirmação, hoje senso comum, de que a grande propriedade, o atraso econômico e o das elites, bem como a agricultura extensiva, não eram indicativos da sobrevivência de traços feudais, já que o capitalismo se apropria de diferentes formas de produção. Portanto, o problema do Brasil foi sempre o capitalismo e sua situação de subordinação econômica orgânica e funcional ao conjunto da economia internacional (PRADO JÚNIOR, 1975, 1996, 2004).

Em suas reflexões sobre a questão agrária, Caio identificou um setor principal, orgânico e exportador, e um setor secundário, inorgânico, de produção familiar voltada para o mercado interno e que não conseguia se 
impor para garantir renda à população. Na relação dialética entre ambos, quando um avança, o outro se retrai. Além disso, na via do desenvolvimento capitalista periférico, o setor principal só pode ser tido como modelo de produtividade. Caio contradizia essa suposição e propunha a domesticação do capitalismo no campo (pela proteção de direitos e sindicalização dos trabalhadores) e o parcelamento da terra (PRADO JÚNIOR, 2000).

\section{Ruy Mauro Marini}

A obra teórica de Ruy Mauro Marini (1932-1997) “antecipou grande parte dos campos de pesquisa e debate das ciências sociais contemporâneas" (DOS SANTOS, 2009, p.22). Sua vida foi a de "um intelectual revolucionário que pensou a realidade de forma rigorosa e do ponto de vista da sua transformação revolucionária" (SADER, 2009, p.27).

Aluno e professor assistente de Guerreiro Ramos, na então Ebap, Ruy Mauro reconhecia sua influência: "crítico irreverente de tudo que cheirasse a oficialismo, eclético incorrigível, aberto às novas ideias que se originavam de Bandung e da Cepal, sua influência sobre mim, naqueles anos, foi absoluta" (MARINI, 2005a, p.60). Graças ao apoio de Guerreiro, Ruy Mauro foi estudar na França no momento em que, no Brasil e na América Latina, a teoria desenvolvimentista estava no auge. Na França, a convivência com militantes argelinos, cambojanos, vietnamitas e da África negra o levou a constatar que as teorias do desenvolvimento, em voga nos EUA e nos centros europeus, eram "instrumento de mistificação e domesticação dos povos oprimidos do Terceiro Mundo e arma com a qual o imperialismo buscava fazer frente aos problemas criados no após-guerra da descolonização" (Ibidem, p.63). Aproximou-se do Partido Socialista e, no Brasil, militou na Organização Revolucionária Marxista - Política Operária (Polop), "primeira expressão no Brasil da esquerda revolucionária que emergia em toda a América Latina” (Ibidem, p.63).

Em 1962 Ruy Mauro se integrou à Universidade de Brasília que, "sob a condução entusiasta de Darcy Ribeiro", rompia com o "imobilismo e o sestro mandarinesco da Universidade tradicional" (Ibidem, p.65). Ali conviveu com colegas e visitantes na formulação da teoria da dependência "que só viria a dar todos os seus frutos após o golpe militar de 1964, quando, limitada em sua militância, a jovem intelectualidade brasileira encontraria tempo e condições para se dedicar plenamente ao trabalho acadêmico" (Ibidem, p.67). Após o golpe, Ruy foi demitido da Universidade de Brasília (UnB), fugindo para o Rio, onde, em maio, foi preso. Solto por habeas corpus do STF, foi sequestrado pela Marinha e entregue ao Exército em Brasília, sendo solto novamente por habeas corpus em dezembro. Após viver na clandestinidade por três meses, asilou-se no México.

No exílio, Ruy Mauro se vinculou ao Centro de Estudos Internacionais do Colégio do México, onde teve como primeira tarefa, escrever um artigo sobre os acontecimentos recentes no Brasil. Nele colocou sobre outras bases a explicação do processo brasileiro pós-1930, ao afirmar que

a ação dos Estados Unidos no Brasil não se podia entender como alheia à realidade nacional, mas como elemento constitutivo dela e [que] só pudera se tornar efetiva (e, portanto, só se explicava) à luz da luta de classes no país, que fincava suas raízes na economia e determinava o jogo político - e da qual as Forças Armadas eram parte plena. (MARINI, 2005a, p.70)

Posteriormente, Ruy Mauro publicou um artigo sobre a dialética do desenvolvimento capitalista brasileiro, abordando a articulação da nossa economia com o sistema imperialista. $\mathrm{O}$ propósito era "desvendar as grandes linhas do processo histórico do Brasil e a gestação das condições da revolução socialista" (Ibidem, p.72). No final de 1967, escreveu Subdesarrollo y revolución, que viria a ser seu trabalho mais conhecido internacionalmente e se inicia com a afirmação de que "a história do subdesenvolvimento latino-americano é a história do desenvolvimento do sistema capitalista mundial" (MARINI, 1969, p.3). No final daquela década, sua presença no México ficou insustentável, tendo sido tomado como um dos agitadores estrangeiros que envenenavam os "bons muchachos mexicanos". Em novembro de 1969 chegou ao Chile para seu segundo exílio. 
No Chile, Ruy Mauro foi morar em Concepción, uma cidade de tradição industrial e ligada a centros mineiros. Ali se originara, em 1965, O Movimento de Esquerda Revolucionária (MIR) - dissidência da Juventude Socialista e com participação de intelectuais trotskistas. "Num ambiente desta natureza é difícil distinguir o que foi atividade acadêmica e o que foi atividade política" (MARINI, 2005a, p.85). Mudou-se para Santiago e aceitou convite para integrar o Centro de Estudos Socioeconômicos (CESO) da Faculdade de Economia da Universidade do Chile. "Sem me subtrair à maré alta de politização que caracterizava então o Chile, vivi ali uma das fases mais produtivas da minha vida intelectual" (Ibidem, p.87). Dialética da dependência saiu em edição mimeografada do CESO, em 1972.

A démarche teórica que ali realizei consistiu, essencialmente, em rejeitar a linha tradicional de análise do subdesenvolvimento, mediante a qual este se captava através de um conjunto de indicadores, os quais, a seu turno, serviam para defini-lo: o resultado não era simplesmente descritivo, mas tautológico. [...] Tentando ir além dessa colocação enganosa, a Cepal avançara pouco, ficando, como elemento válido de sua elaboração, a crítica à teoria clássica do comércio internacional e a constatação das transferências de valor que a divisão internacional do trabalho propicia, em detrimento da economia latino-americana.

Em vez de seguir esse raciocínio e fiel a meu princípio de que o subdesenvolvimento é a outra cara do desenvolvimento, eu analisava em que condições a América Latina havia-se integrado ao mercado mundial e como essa integração: a) funcionara para a economia capitalista mundial e b) alterara a economia latino-americana. (Ibidem, p.90-91)

A dependência é uma "relação de subordinação entre nações formalmente independentes, em cujo marco as relações de produção das nações subordinadas são modificadas ou recriadas para assegurar a reprodução ampliada da dependência". Sua superação só pode, portanto, se dar quando da "supressão das relações de produção nela envolvidas" (MARINI, 2005b, p.141). No núcleo central de como se reproduz o capitalismo dependente, encontra-se a superexploração do trabalho: uma forma de exploração na qual são negadas ao trabalhador as condições necessárias para repor o desgaste de sua força de trabalho. O sacrifício do consumo individual dos trabalhadores em favor da exportação para o mercado mundial deprime os níveis de demanda interna e provoca a necessidade de expansão para o exterior, o que engendra a ressurreição do modelo agroexportador e políticas agressivas de competição internacional, especialmente, em projetos direcionados para a economia regional. A expressão acentuada dessas tendências no Brasil levou Ruy Mauro a qualificá-las de subimperalismo.

Após o golpe de 1973, no Chile, Ruy Mauro foi para o terceiro exílio, na Europa e, novamente, no México. Em 1978, regressou ao Brasil, mantendo suas ligações e parcerias intelectuais no México.

\section{Darcy Ribeiro}

Estudou o Brasil e os brasileiros, bem como o contexto da América Latina, que para ele tinha uma "unidade essencial com nosso processo civilizatório, apesar dos fatores de diversificação". Darcy Ribeiro (1922-1997) foi antropólogo, educador, criador de universidades, romancista e político (FERRAZ, 2008, p.10).

Obteve uma bolsa para estudar sociologia e política na USP: "queria trabalhar como sociólogo, pois na época estava mais interessado na sociedade nacional, como um todo, do que apenas nos índios". "Na época, eu era um jovenzinho intelectual, comunista, esquerdista, feroz. Tinha a impressão de que o papel que me caberia devia ser o de revolucionário profissional" (RIBEIRO, 2007, p.81). Foi liberado do ativismo pelo próprio PCB, que ponderou que ele seria mais útil como futuro cientista do que como militante. Sobre seus tempos na USP e sua convivência com Lévi-Strauss e Florestan Fernandes (estudante como ele), diz Darcy (Ibidem, p.84-87):

Eu, pobre estudante mineiro, querendo ser aplicado, mergulhei naquilo que, para mim, era a própria sabedoria. Na verdade, depois percebi, tratava-se de uma técnica moderna com respeito à erudição arcaica de que eu saia, mas era igualmente alienadora. [...] Parecia absurdo tanto esforço de pesquisa direta ou bibliográfica, tanta construção metodológica de andaimes maiores que a própria 
obra para versar sobre temas que não tinham a menor relevância social e se situavam a uma imensa distância da nossa problemática. $O$ interesse do Florestan trotsquista, o meu interesse de estudante comunista, era a sociedade nacional, a revolução. [...] Naquela época, duas coisas me salvaram do academicismo fútil. Primeiro, o fato de ser comunista de ocasião, impedindo que eu me desvinculasse da história, e me desinteressasse do mundo real, concreto, meu. [...] O segundo fato foi puramente acidental. Minha bolsa na escola era de trabalho. Assim é que tive que ler um enorme número de obras de interesse social, toda literatura que envolvesse sociologia. [...] assim, tomei contato com o pensamento brasileiro que no meu curso jamais seria objeto de interesse, senão, talvez, como exemplos desprezíveis de filosofia social. [...] Como veem, o ativismo político, a herança brasilianista e o interesse literário provavelmente impediram que eu me convertesse num acadêmico completo, perfeitamente idiota.

Como etnólogo, por 10 anos Darcy viveu entre os índios - decifrando seu modo de existir e pensar -, fundou o Museu do Índio, estabeleceu os princípios que levaram à criação do Parque Indígena do Xingu e escreveu os seis volumes de Estudos de antropologia da civilização (mais de 150 edições, em várias línguas). Como educador, lutou incansavelmente pela escola pública e gratuita de tempo integral, criou as universidades de Brasília (UnB) e Estadual do Norte Fluminense (Uenf), organizou a Universidade Aberta do Brasil, andou pela América Latina reformando universidades e foi autor da Lei de Diretrizes e Bases da Educação, que leva seu nome. Como romancista escreveu, no exílio, os belíssimos Maíra e $O$ mulo, entre outros. Como político e administrador público, foi chefe da Casa Civil e ministro da Educação do governo Jango, candidato ao governo do Rio de Janeiro, vice-governador e secretário de Estado no governo Brizola, além de senador da República (FERRAZ, 2008; FUNDAÇÃO DARCY RIBEIRO, 1997). Falando sobre sua inserção na política, dizia que nunca tinha gostado e que, no fundo, era político por razões éticas: "Um poeta inglês pode ser só poeta. Mas num país com o intestino à mostra, como o Brasil, o intelectual tem a obrigação de tomar posição (RIBEIRO, 2007, p.191).

O processo civilizatório (RIBEIRO, 1987) foi, segundo Darcy (RIBEIRO, 2007, p.223), uma tentativa de compreender 10 mil anos de história humana, "de forma tal que nós mesmos também pudéssemos ser compreendidos". O objetivo foi escrever uma teoria da história, com base na ideia de que, considerando o desenvolvimento da tecnologia, era possível fazer uma seriação da sociedade melhor do que as até então existentes. Em As Américas e a civilização (RIBEIRO, 1970a) buscou respostas para a pergunta sobre os motivos pelos quais o Brasil havia ficado para trás no processo de desenvolvimento. Para isso, examinou 500 anos de história americana. Insatisfeito com o resultado, escreveu $O$ dilema da América Latina (RIBEIRO, 1988), onde propôs uma tipologia de classes sociais que considerava também as formas de ação política. Em $O s$ índios e a civilização (RIBEIRO, 1970b) desenvolveu o conceito de "transfiguração étnica", que é "o processo pelo qual os povos se fazem e se transformam ou se desfazem" (RIBEIRO, 2007, p.227).

Sua última obra editada foi O povo brasileiro (RIBEIRO, 1996, p.17 e 23), cuja escrita foi considerada por ele seu maior desafio. Darcy estuda a gestação do nosso povo, "surgido do entrechoque e do caldeamento do invasor português com índios silvícolas e campineiros e com negros africanos, uns e outros aliciados como escravos". Estuda também as linhas de diversificação que plasmam nossos modos regionais de ser e critica o sistema institucional, notadamente, o da propriedade fundiária e o regime de trabalho, "no âmbito do qual o povo brasileiro surgiu e cresceu, constrangido e deformado".

Eterno indignado com este país de "moer gente", Darcy vaticinava em uma entrevista realizada em 1979,

Ou o Brasil toma conta de si mesmo e organiza sua vida para que os brasileiros possam comer, vestirse, educar-se, para chegar ao ano 2000 como um povo livre e minimamente próspero, ou se continua pelo caminho do desenvolvimento associado e do latifúndio irresponsável para fracassarmos na futura civilização. (RIBEIRO, 2007, p. 107) 
Nem lhes explicaremos que somente é possível efetuar a libertação real no mundo real e através dos meios reais; [...] que não é possível libertar os homens enquanto não estiverem em condições de obter alimentação e bebida, habitação e vestimenta, em qualidade e quantidade adequada.

KARL MARX e FRIEDRICH ENGELS

Além de seus diferentes matizes ideológicos, trajetórias pessoais, estilos e personalidades, escolhas intelectuais e de formas de luta, esses admiráveis brasileiros compartilhavam, junto com tantos outros intérpretes do Brasil em sua tradição crítica, um problema central: como enfrentar e estancar o caminho perverso de mais capitalismo, mais dependência e mais miséria.

Cada um, a seu jeito, colocou-se no dever de denunciar a ambivalência do progresso destruidor de gentes e de lutar pela possibilidade de outros caminhos. Deixam para nós, além de lições de vida, pelo modo como despudorada e destemidamente aliaram a produção acadêmica ao ativismo político, uma agenda de estudos que pede para ser retomada. Décadas se passaram, os contexto mundial, latino-americano e nacional mudaram, os atores sociais e políticos também, enquanto a universidade se amesquinhou ainda mais. No entanto, os temas que foram centrais para esses intelectuais continuam presentes e agudizados: nossos problemas quanto à relação com o capitalismo e a economia internacional, a questão agrária e o paradoxo entre o latifúndio do agronegócio exportador e a pequena propriedade produtora de alimentos, o acesso à educação qualificada de contingentes massivos de crianças miseráveis e à universidade de que continuamos precisando, bem como nossa relação com a América Latina, que na retórica é pró-integração, mas na prática é cada vez mais subimperialista.

Antes de encerrar, é indispensável trazer Maurício Tragtenberg (1929-1998) para este diálogo. Maurício, também militante e acadêmico, foi precioso e raro personagem em nosso campo disciplinar. Além de seu legado teórico - orientado tanto para compreender a relação entre organização burocrática e o capitalismo, quanto pela convicção da possibilidade de superá-la através da auto-organização dos oprimidos -, Maurício também deixa lições de ativismo. Na década de 1940, já se encontrava atuando no movimento libertário de São Paulo, e assim se manteve ao longo de sua vida. Nos anos 1970, vinculou-se às iniciativas autônomas de base surgidas no contexto do Movimento Contra a Carestia e também viveu o processo de reorganização do movimento operário, participando intensamente da oposição sindical metalúrgica, que considerava uma oposição à estrutura sindical vigente. "Em muitas greves daqueles tempos poderíamos vê-los - ele e Beatriz [sua companheira] juntos - percorrendo piquetes de madrugada com sanduíches e café quente, verdadeiramente abençoados" (MOREL, 1999, p.283).

Por ser capaz de manter sua coerência e sua utopia em circunstâncias nas quais muitos outros falharam ou desistiram; por ter sido capaz de consagrar sua vida e sua carreira ao serviço de suas ideias, muitas vezes, em detrimento de vantagens ou privilégios materiais imediatos; por ter sido capaz de manter a coerência intelectual e a flexibilidade mental durante 55 anos de vida intelectual ativa [...]; somos gratos a Maurício. (MOREL, 1999, p.287)

Gratidão extensiva a Caio Prado Júnior, a Ruy Mauro Marini, a Darcy Ribeiro e a tantos outros intelectuais que foram contemporâneos de seu tempo, solidários com sua gente e comprometidos com a transformação da realidade. No entanto, ser grato é pouco. O silêncio imposto pela ditadura militar e, posteriormente, pelo discurso monológico do mercado total colocaram a tradição crítica brasileira no esquecimento. As novas gerações desconhecem autores e ideias. Nunca ouviram falar! Quando essa tradição é mencionada, usualmente, vem acompanhada de acusações de anacronismo e de saudosismos de projetos fracassados e sonhos frustrados. Portanto, honrar nossa tradição crítica exige que compareçamos ao encontro marcado com as gerações que nos precederam, que ouçamos o apelo messiânico dos seus projetos e sonhos de transformação do real. 


\section{Referências}

BENJAMIN, Walter. Sobre o conceito de história. In: Obras escolhidas: magia e técnica, arte e política. Rio de Janeiro: Brasiliense, 1996. p.222-232.

DOS SANTOS, Theotônio. Ruy Mauro Marini: um pensador latino-americano. In: MARTINS, C. E.; VALENCIA, A. S. América Latina e os desafios da globalização: ensaios dedicados a Ruy Mauro Marini. Rio de Janeiro: PUC-Rio; Campinas: Boitempo, 2009. p.21-26. FERRAZ, Isa G. Introdução. In: (Org.). Darcy Ribeiro: utopia Brasil. São Paulo: Hedra, 2008.

FREIRE, Paulo. Extensão ou comunicação. Rio de Janeiro: Paz e Terra, 1979.

FUNDAÇÃO DARCY RIBEIRO. Sobre Darcy Ribeiro. In: FUNDAR (Ed.). Darcy Ribeiro: Entidades. Porto Alegre: LCtPM, 1997. p.142-146.

GRAMSCI, Antonio. Cadernos do cárcere: introdução ao estudo da filosofia de Benedetto Croce. Rio de Janeiro: Civilização Brasileira, 2006.

KONDER, Leandro. Intelectuais brasileiros \&t marxismo. Belo Horizonte: Oficina dos Livros, 1991.

LÖWY, Michael. Por um marxismo crítico. In: BENSAID, D. Marxismo, modernidade e utopia. São Paulo: Xamã, 2000. p. 58-67.

MARINI, Ruy Mauro. Subdesarrollo y revolución. México: Siglo Veintiuno Editores, 1969.

135.

Memória. In: TRASPADINI, R.; STEDILE, J. P. (Org.). Ruy Mauro Marini: vida e obra. São Paulo: Expressão Popular, 2005a. p.57-

Dialética da dependência. In: TRASPADINI, R.; STEDILE, J. P. (Org.). Ruy Mauro Marini: vida e obra. São Paulo: Expressão Popular, 2005b. p.181-194.

MARX, Karl. Teses sobre Feurbach. In: .; ENGELS, F. A ideologia alemã (Feuerbach). São Paulo: Hucitec, 1999. p.11-15.

; ENGELS, Friedrich. A ideologia alemã. In: MARX, K.; ENGELS, F. A ideologia alemã (Feuerbach). São Paulo: Hucitec, 1999. p.15121.

MOREL, José Carlos. O. Mauricio Tragtenberg: a solidariedade de classe e as lutas sociais em São Paulo. In: ACCIOLLY e SILVA, D.; MARRACH, S. A. (Org.). Maurício Tragtenberg: uma vida para as ciências humanas. São Paulo: Unesp, 1999. p.257-288.

PINHEIRO, Paulo Sérgio. Caio Prado Júnior. Isto É, São Paulo, 7 jul. 1982.

PRADO JÚNIOR, Caio Prado. Evolução política do Brasil. São Paulo: Brasiliense, 1975.

Formação do Brasil contemporâneo. São Paulo: Brasiliense, 1996.

A questão agrária no Brasil. São Paulo: Brasiliense, 2000.

A revolução brasileira. São Paulo: Brasiliense, 2004.

RIBEIRO, Darcy. As Américas e a civilização: processo de formação e causas do desenvolvimento cultural desigual dos povos americanos. Rio de Janeiro: Civilização Brasileira, 1970a.

Os índios e a civilização: a integração das populações indígenas no Brasil moderno. Rio de Janeiro: Civilização Brasileira, $1970 b$.

0 processo civilizatório: etapas da evolução sociocultural. 10.ed. Petrópolis: Vozes, 1987.

0 dilema da América Latina: estruturas de poder e forças insurgentes. 5.ed. Petrópolis: Vozes, 1988.

0 povo brasileiro: a formação e o sentido do Brasil. 2.ed. São Paulo: Companhia das Letras, 1996.

Entrevistas. In: REIS, R.; COHN, S; CAMPOS, S. (Org.). Darcy Ribeiro - encontros. Rio de Janeiro: Beco do Azougue, 2007. p.12-

232.

SADER, Emir. Ruy Mauro, intelectual revolucionário. In: MARTINS, C. E.; VALENCIA, A. S. América Latina e os desafios da globalização: ensaios dedicados a Ruy Mauro Marini. Rio de Janeiro: PUC-Rio; Campinas: Boitempo, 2009. p.27-36. 
SECCO, Lincoln. Caio Prado Júnior: o sentido da revolução. Campinas: Boitempo, 2008.

VÁSQUEZ, Adolfo Sánchez. Filofosofia da práxis. Buenos Aires: Clacso; São Paulo: Expressão Popular, 2007.

WIDER, M. C. Caio Prado Júnior: um intelectual irresistível. São Paulo: Brasiliense, 2007. 